\title{
A new method for deriving aerosol solar radiative forcing and its first application within MILAGRO/INTEX-B
}

\author{
K. S. Schmidt ${ }^{1}$, P. Pilewskie ${ }^{1}$, R. Bergstrom ${ }^{2}$, O. Coddington ${ }^{1}$, J. Redemann ${ }^{2}$, J. Livingston ${ }^{3}$, P. Russell ${ }^{4}$, \\ E. Bierwirth $^{5}$, M. Wendisch ${ }^{5}$, W. Gore ${ }^{4}$, M. K. Dubey ${ }^{6}$, and C. Mazzoleni ${ }^{6,7}$ \\ ${ }^{1}$ Laboratory for Atmospheric and Space Physics, Boulder, CO, USA \\ ${ }^{2}$ Bay Area Environmental Research Institute, Sonoma, CA, USA \\ ${ }^{3}$ SRI International, Menlo Park, CA, USA \\ ${ }^{4}$ NASA Ames Research Center, Moffett Field, CA, USA \\ ${ }^{5}$ Leipzig Institute for Meteorology, University of Leipzig, Germany \\ ${ }^{6}$ Los Alamos National Laboratory, Los Alamos, NM, USA \\ ${ }^{7}$ Michigan Technological University, MI, USA
}

Received: 14 January 2010 - Published in Atmos. Chem. Phys. Discuss.: 3 February 2010

Revised: 19 June 2010 - Accepted: 6 July 2010 - Published: 24 August 2010

\begin{abstract}
We introduce a method for deriving aerosol spectral radiative forcing along with single scattering albedo, asymmetry parameter, and surface albedo from airborne vertical profile measurements of shortwave spectral irradiance and spectral aerosol optical thickness. The new method complements the traditional, direct measurement of aerosol radiative forcing efficiency from horizontal flight legs below gradients of aerosol optical thickness, and is particularly useful over heterogeneous land surfaces and for homogeneous aerosol layers where the horizontal gradient method is impractical. Using data collected by the Solar Spectral Flux Radiometer (SSFR) and the Ames Airborne Tracking Sunphotometer (AATS-14) during the MILAGRO (Megacity Initiative: Local and Global Research Observations) experiment, we validate an over-ocean spectral aerosol forcing efficiency from the new method by comparing with the traditional method. Retrieved over-land aerosol optical properties are compared with in-situ measurements and AERONET retrievals. The spectral forcing efficiencies over ocean and land are remarkably similar and agree with results from other field experiments.
\end{abstract}

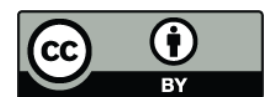

Correspondence to: K. S. Schmidt (sebastian.schmidt@lasp.colorado.edu)

\section{Introduction}

In this paper, we study aerosol radiative properties such as spectral single scattering albedo and asymmetry parameter as well as spectral radiative forcing from the MILAGRO (Megacity Initiative - Local and Global Research Observations) experiment (Molina et al., 2010) in March 2006. We use irradiance and aerosol optical thickness (AOT) measurements made by the Solar Spectral Flux Radiometer (SSFR, Pilewskie et al., 2003) and the 14-channel Ames Airborne Tracking Sunphotometer (AATS-14, Livingston et al., 2009). These instruments were mounted on the NASA J-31 aircraft (based in Veracruz, Mexico) that conducted 13 research flights over the Gulf of Mexico and the Mexico City area. In previous studies, the combination of irradiance and AOT measurements was used to derive the so-called aerosol radiative forcing efficiency (Pilewskie et al., 2003; Redemann et al., 2006). This quantity describes the change of net irradiance, $\Delta F$, per change of AOT, $\Delta \tau$. Despite the broad spatial and temporal variability inherent in aerosol optical properties, there are some indications that the relative spectral forcing efficiency (forcing efficiency normalized by incident irradiance on top of the aerosol layer) lies within typical ranges. This property makes forcing efficiency a convenient concept for characterizing aerosol radiative effects even when little is known about the aerosol microphysical and optical properties. This occurs, for example, in satellite observations where usually only optical thickness is available. Aerosol radiative forcing is one of the least constrained observables

Published by Copernicus Publications on behalf of the European Geosciences Union. 


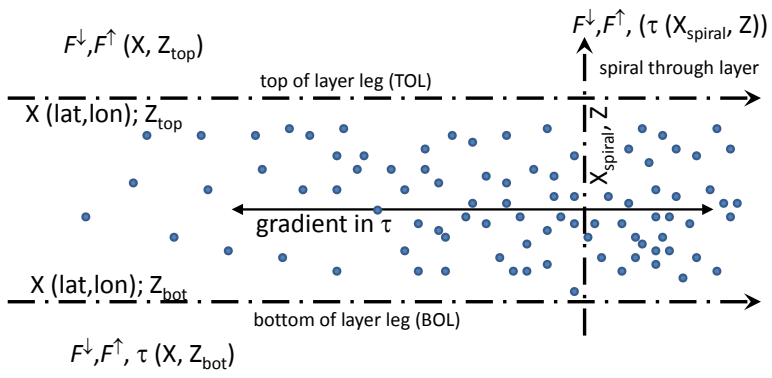

Surface

Fig. 1. A horizontal flight leg below an aerosol gradient can be used to measure aerosol bottom of layer (BOL) forcing efficiency directly. An additional leg above the layer that traces back the leg below provides the layer absorption and top of layer (TOL) forcing efficiency. The two stacked legs together are also referred to as flux divergence legs. The vertical profile or the points along the flux divergence leg are exploited by the new method.

in the global energy budget, in part because it is often derived indirectly, that is, calculated from aerosol optical properties (optical thickness, single scattering albedo and asymmetry parameter) which are in turn obtained from remote sensing techniques or in-situ measurements. The instrument uncertainties and various assumptions in aerosol retrievals propagate into the error bars of the radiative effects (Magi et al., 2008). Measuring the radiative forcing directly is impossible since it would require simultaneous irradiance measurements in presence and in absence of a radiative perturbation (in this case, the aerosol layer). However, irradiance measurements in presence of a gradient in optical thickness provide the most direct way of constraining forcing efficiency, thus circumventing the need for detailed aerosol optical properties.

The gradient method requires that changes in net irradiance and AOT observed below an aerosol layer be linearly correlated. The forcing efficiency can then be obtained directly from the slope of the regression line. The measurement geometry is illustrated in Fig. 1. Typically, only the bottom of layer (BOL) forcing efficiency is measured for the gradient method. Obtaining top of layer (TOL) forcing efficiency requires an additional flight leg above the layer along the same ground track as the BOL leg. The net irradiance measured above the layer can then be correlated with the AOT measurements from the leg below. The difference between TOL and $\mathrm{BOL}$ forcing is equal to the absorption within the aerosol layer; in the same way, it is atmospheric absorption that connects top of atmosphere (TOA) and surface forcing of an atmospheric constituent.

If properties other than AOT (e.g., surface albedo, aerosol single scattering albedo, sun angle) change during the measurement, the gradient method cannot be rigorously applied. In particular, a heterogeneous surface makes the gradient method impractical because changes in net irradiance are caused both by changes in the underlying surface albedo as well as in aerosol optical thickness above the leg. Also, the gradient method cannot be applied for homogeneous aerosol layers with negligible gradients in AOT (Redemann et al., 2006).

Our new method was developed as an alternative approach that can be used over inhomogeneous land surfaces and in case of homogeneous aerosol layers. It has been adapted from a method that was originally developed for deriving aerosol single scattering albedo from absorption measurements (Bergstrom et al., 2007; Russell et al., 2002). The new method uses spectral irradiance and AOT that are measured in a vertical profile (see Figure 1). The aerosol single scattering albedo, asymmetry parameter, and surface albedo are derived from the upward, downward, and net spectral irradiance above and below the layer by iteratively adjusting these values in a radiative transfer model until the modeled irradiance converges to the measured irradiance at flight altitude. The AOT spectrum is required as model input. The retrieved values are then used to calculate the TOL and BOL forcing efficiencies. The new method is not limited to instantaneous forcing efficiencies that are dependent on solar zenith angle: When aerosol single scattering albedo, asymmetry parameter, and surface albedo are known, spectral and broadband forcing efficiencies can be calculated for any time and solar zenith angle, or as a diurnally-averaged quantity (Russell et al., 1997).

There are two advantages to this new approach: (1) It does not require a horizontal gradient in AOT since the ascent or descent (ramp or spiral) provides a vertical change in AOT and net irradiance even for very homogeneous layers, such as arctic haze events. (2) By restricting a spiral to a radius on the order of a few miles, the impact of variable surface albedo on net irradiance is minimized. There are also disadvantages: (1) Irradiance data from spirals are prone to attitude-correction errors if the optical inlets are not actively stabilized (Wendisch et al., 2001; Bucholtz et al., 2008). This can be partly remedied by flying spirals that have short straight and level sections. (2) Even when limiting the horizontal coverage of the vertical profiles, a horizontal component reflecting variability in the underlying surface or in aerosol parameters may remain; also, the new method requires stability of the aerosol properties during the time of the measurement. (3) Throughout the profile, the footprint (the circle from within which half of the signal originates) of the downward looking irradiance sensor increases with altitude, introducing sensitivity to heterogeneous surface and aerosol conditions.

In Sect. 2, we introduce the measurements and the new method. For one over-ocean case, we compare results for aerosol spectral forcing efficiency with those obtained directly from the gradient method. For one case over land, we show that heterogeneities in land surface albedo prohibit the use of the gradient method, and compare single scattering albedo and asymmetry parameter derived from the new method with in-situ measurements and with retrievals from 

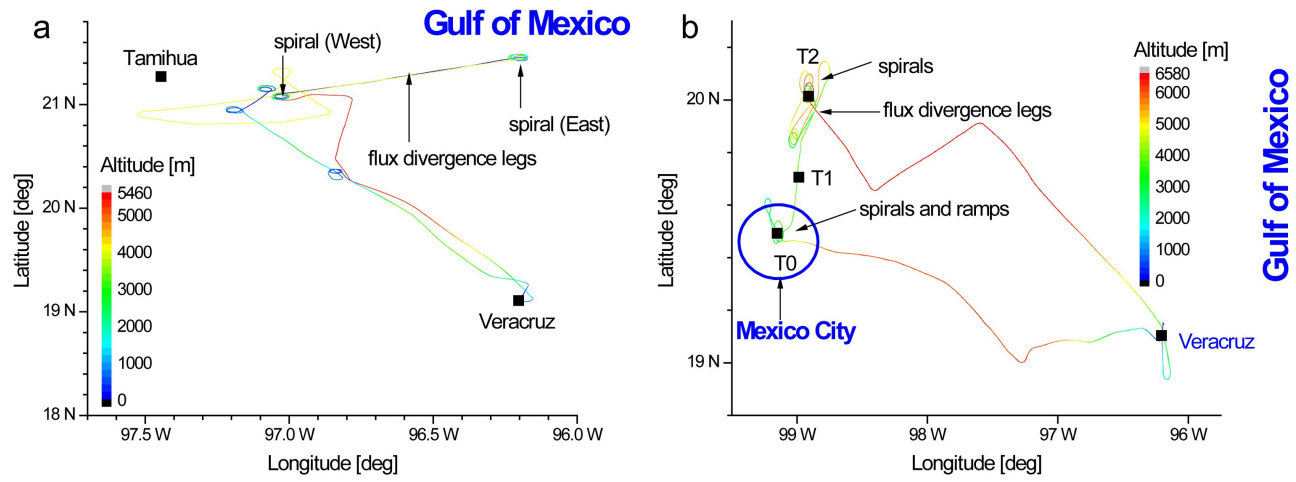

Fig. 2. Flight tracks of the NASA J-31 aircraft on 13 (a) and 19 March 2006 (b), color-coded for flight altitude. T0, T1, and T2 are ground sites of the experiment that were equipped with sun-sky photometers. Tamihua is a permanent AERONET site.

Aerosol Robotic Network (AERONET) stations in the Mexico City area. In Sect. 3, we present detailed results and put them in the context of other measurements. In Sect. 4, we discuss some of the measurements of surface albedo, and its variability (see also Coddington et al., 2008). Sect. 5 contains discussion of results, conclusions, and future work.

\section{Data and methodology}

\subsection{The MILAGRO experiment}

The objectives of the MILAGRO experiment are described by Molina et al. (2010). The J-31 was dedicated to radiometric measurements and remote-sensing of aerosol layers in the Mexico City area (5 flights) and over the Gulf of Mexico (8 flights). Most flight segments described in this paper were conducted under cloud-free conditions. Figure 2 shows the flight tracks of the J-31 on 13 March 2006 (a: case over ocean), and on 19 March 2006 (b: case over land). The flight altitude is color-coded. Within this study, we used two cases over ocean (10 and 13 March 2006), and two cases over land (6 and 19 March 2006). Normal flight patterns included lowaltitude runs to characterize AOT gradients. When possible, a high-altitude (above-aerosol) leg along the same groundtrack was added for aerosol absorption and TOL forcing efficiency measurements. Over sea, the low-level leg could be flown at 30-40 m above sea level (ASL). Over land, air-traffic control restricted the minimum flight altitude, and the airplane was usually not permitted below $300 \mathrm{~m}$ above ground level (AGL). Co-located high- and low-level legs and spirals were flown even over land. On 19 March 2006, the evolution of aerosol optical properties was traced from the source (around the ground site T0, Mexico City), to T1 and T2 (regions NE of Mexico City that were affected by urban outflow). In Fig. 2b, the labels T0, T1, and T2 denote ground stations where extensive aerosol in-situ observations and limited radiometric measurements were made. In addition to the existing AERONET station in Tamihua (northwest of Ver- acruz), sun-sky photometers were placed at T0, T1, and T2 for the duration of the field experiment.

\subsection{Radiative quantities}

\subsubsection{Optical thickness and Ångström parameter}

The aerosol optical thickness, $\tau$, is defined as the columnintegrated extinction. It is comprised of the aerosol scattering and absorption optical thickness, $\tau_{\text {sca }}$ and $\tau_{\text {abs }}: \tau_{\text {tot }}=\tau_{\text {sca }}+$ $\tau_{\text {abs. }}$. The ratio between scattering and total optical thickness is the column aerosol single scattering albedo: $\varpi=\tau_{\text {sca }} / \tau_{\text {tot }}$. The spectral dependence of the AOT contains information about the particle size distribution. The Ångström parameter, $a$, describes the decrease of AOT with wavelength $\lambda$ : $\tau(\lambda)=\tau\left(\lambda_{0}\right) \times\left(\lambda / \lambda_{0}\right)^{-a}$. For small particles, $a$ is large (steep spectral dependence); for large particles, the optical thickness does not strongly depend on wavelength and $a$ is small.

\subsubsection{Irradiance and related quantities}

Irradiance comprises the radiative energy per unit time and area. The net irradiance, $F$, (or net flux density) is the difference between downward and upward irradiance, $F^{\downarrow}$ and $F^{\uparrow}: F=F^{\downarrow}-F^{\uparrow}$. The albedo is the ratio between upward and downward irradiance: $\alpha=F^{\uparrow} / F^{\downarrow}$. The layer-absorbed irradiance is obtained from the difference of net irradiance above and below the layer, provided that no radiation escapes horizontally (Chandrasekhar, 1960). This is sometimes referred to as flux divergence, although flux divergence also includes horizontal contributions. We ignore horizontal heterogeneities and thus horizontal transport of radiation in our one-dimensional approach, assuming that the studied aerosol layers are homogeneous (which is only an approximation as will be discussed below). In radiative transfer calculations, the Mie scattering phase function is often replaced by the Henyey-Greenstein (HG) phase function that can be represented by a single value, the asymmetry parameter, $g$. The asymmetry parameter is the first moment of the scattering 
phase function and is related to the mean scattering direction ( $g=1$ : entirely forward, $g=-1$ : entirely backward). For irradiance calculations in air or aerosol layers, the HG approximation is sufficient (see, however, Wiscombe and Grams, 1976; Coakley and Chylek, 1975). In such cases the only parameters needed for describing the air or aerosol optical properties are AOT, single scattering albedo, and asymmetry parameter.

\subsection{Radiometric measurements}

For this study, aerosol optical thickness was obtained from AERONET stations and AATS-14. The AERONET sunsky retrievals (Dubovik et al., 2000) provide wavelengthdependent AOT (and thus Ångström parameter and size information), aerosol single scattering albedo (related to absorption), and asymmetry parameter (which also contains size information). The latter two retrieved quantities are possible for a minimum mid-visible AOT of 0.4 among other conditions. The airborne sunphotometer, AATS-14 (Russell et al., 1999; Livingston et al., 2009), provided total aerosol optical thickness at 14 wavelengths (and thus Ångström parameter). The AATS-14 data were masked for cloud occurrences and corrected for molecular scattering and gas absorption (Livingston et al., 2009). A pre- and post-experiment calibration at Mauna Loa, Hawaii, showed a radiometric stability of better than $0.5 \%$ in most channels, translating into AOT uncertainties of 0.002 to 0.006 .

The SSFR measured downward and upward spectral irradiance over the spectral range $350-2100 \mathrm{~nm}$, with $8-12 \mathrm{~nm}$ spectral resolution. Both optical inlets were fix-mounted on the aircraft fuselage and connected to the spectrometer system through optical fibers. The wavelength calibration and the optical inlet correction factor related to the incidence angle (so-called cosine-response) were determined in the laboratory prior to the field experiment. An absolute spectral calibration with a NIST-traceable light source (1000 W lamp) was performed before and after the experiment. The nominal radiometric uncertainty is $3-5 \%$ across the spectral range. During the field experiment, the stability of the calibration was monitored with field-calibrators; the flight-to-flight stability was better than $1 \%$.

The data were corrected for the angular response of the light collectors and for changes in downward irradiance due to aircraft attitude. The attitude correction was necessary because the light collector reference plane (i.e., SSFR horizon) did not always coincide with the actual horizon due to changes in aircraft pitch, roll, and heading. The correction method (Bannehr and Schwiesow, 1993; Bucholtz et al., 2008) uses the measured attitude angles, offset angles between the aircraft inertial reference system and the optical inlet plane, and the time lag between the GPS time and SSFR time. The maximum angular deviation of the aircraft (and SSFR) attitude with respect to the horizon was limited to $3^{\circ}$. This filter was required because the upward irradiance could not be corrected and because the downward correction is limited to small deviations from horizontal aircraft alignment and cannot account for effects from clouds, the surface, or nearby mountains. The filter was relaxed only if no horizontal sections with low roll angles were encountered (in spiral measurements). The error introduced into irradiance by deviating from horizontal alignment was analyzed by Wendisch et al. (2001) and Bucholtz et al. (2008). For the encountered solar zenith angles, a misalignment of $1^{\circ}$ results in $1 \%$ uncertainty in downward irradiance. Additional uncertainty is introduced by the angular response of the light collectors which are also affected by horizontal misalignment. This error in net irradiance, as well as the attitude-related error for the upward irradiance, can only be quantified empirically. From spiral measurements, the attitude-related systematic error is estimated to be $2 \%$.

\subsection{Derivation of aerosol radiative forcing efficiency}

\subsubsection{Gradient method}

The instantaneous aerosol solar forcing efficiency (Redemann et al., 2006) is derived from simultaneous changes in aerosol optical thickness at a mid-visible wavelength $(499 \mathrm{~nm}), \tau_{499}$, and spectral net irradiance, $F_{\lambda}$. Both quantities are linearly correlated and the resulting slope is the spectral forcing efficiency $E_{\lambda}$ :

$E_{\lambda}=d F_{\lambda} / d \tau_{499}$

The relative forcing efficiency: $e_{\lambda}=E_{\lambda} / F_{\lambda}^{\downarrow} \times 100 \%$ (where $F_{\lambda}^{\downarrow}$ is the downwelling irradiance at the top of the layer) can be used to compare aerosol radiative forcing from different experiments since it is fairly independent of aerosol loading (AOT) and, in contrast to $E$, is also independent of downwelling flux at layer top (which varies with solar zenith angle, time of the year, etc.). Prior to regressing irradiance and optical thickness, the downward irradiance must be corrected for changes in solar zenith angle (SZA). Redemann et al. (2006) use a correction formula from Russell et al. (1999) that requires radiative transfer calculations. Here, we use a more straightforward approach: The corrected irradiance for $\mu_{0}=\cos \left(\operatorname{SZA}\left(t_{0}\right)\right)$,

$F^{\downarrow}\left(\mu_{0}\right)=F^{\downarrow}(\mu(t)) \times\left(\mu_{0} / \mu(t)\right)$

is close to the uncorrected irradiance $F^{\downarrow}(\mu(t))$ if the time span $\Delta t$ of the measurement is short and thus if the range of $\mu$ values $(\Delta \mu)$ is small; $\mu_{0}$ is chosen in the center of this range $\left(\mu_{0} \approx<\mu>\right.$ ). Redemann et al. (2006) find that $\Delta \tau>0.05$ and $\Delta \mu / \Delta \tau \ll 1$ are necessary conditions for the gradient method to work. The latter condition does not hold when a gradient occurs over a long distance or time.

Figure 3 illustrates results using the gradient method for 13 March 2006 where SSFR net irradiance is plotted versus AATS-14 AOT (both at $499 \mathrm{~nm}$ wavelength). Measurements below the aerosol gradient are shown as black open 
circles. They are grouped in two domains that correspond to optical thickness values of about 0.15 and 0.27 (Fig. 6 shows optical thickness as a function of longitude). These two domains were separated by a dissipating cumulus cloud around $96.6^{\circ} \mathrm{W}$. Both irradiance and optical thickness data were screened for clouds in order to avoid cloud edge effects. For AATS-14, a cloud flag was created based on the spatial variability of transmission measurements at a resolution nine times higher than the resolution of reported AATS AOT (Redemann et al., 2009). For SSFR, cloud-contaminated data were removed manually.

The slope of the linear regression (black line) represents the BOL forcing efficiency. Since the range in optical thickness was below the limit of applicability of the gradient method $(\Delta \tau \approx 0.05)$ for the individual legs, we combined both domains in the regression. This is not entirely justified: As we will show later (Sect. 3, Figs. 6 and 7), the two domains belong to two different air masses with different single scattering albedo and aerosol asymmetry parameter. When regressing the BOL measurements individually (not shown), different slopes and thus forcing efficiencies are obtained (higher in the western part, and lower in the eastern part). The same is true for the TOL forcing efficiencies.

The closed circles show the TOL measurements that retraced the low-level leg along the same flight track. The AOT values used for the TOL leg were obtained from the closest latitude and longitude along the low-level leg since AATS14 only measures the fraction of AOT that is located above the aircraft. In Fig. 2a, the coordinated legs are labeled "flux divergence legs". They are delimited by an upward spiral in the east and a downward spiral in the west. The difference between the mean TOL net irradiance in the western and eastern domain (2\%) can be attributed to different single scattering albedo values in the two air masses (Fig. 6).

\subsubsection{New method}

The starting point for the new approach are two pairs of irradiance spectra from SSFR: one above $\left\{F_{\text {top }}^{\uparrow}, F_{\text {top }}^{\downarrow}\right\}$ and one below $\left\{F_{\text {bot }}^{\uparrow}, F_{\text {bot }}^{\downarrow}\right\}$ an aerosol layer and its spectral optical thickness $\tau$, which can be obtained from a selected latitude and longitude (denoted $X$ in Fig. 1) along the TOL leg (altitude $\mathrm{Z}_{\mathrm{top}}$ ) and BOL leg (altitude $\mathrm{Z}_{\mathrm{bot}}$ ) of flux divergence legs, or from vertical profile measurements. The red symbols in Fig. 3 show attitude corrected net irradiance vs. AOT measurements from a spiral vertical profile near the western end of the flux divergence leg on 13 March 2006. In this case, the slope of the regression (dash-dotted red line) cannot be used to determine forcing efficiency directly because during the profile, changing portions of the aerosol layer were above and below the aircraft. At $\tau=\tau_{\text {bot }}=0.29$ (this is at the bottom of the spiral below the layer), the net irradiance on the regression line is $1.24 \mathrm{~W} \mathrm{~m}^{-2} \mathrm{~nm}^{-1}$ - the same value as on the low-level gradient leg at $\tau=0.29$. On top of the spiral, at $\tau=\tau_{\text {top }}=0$, the entire aerosol layer is below the aircraft, and

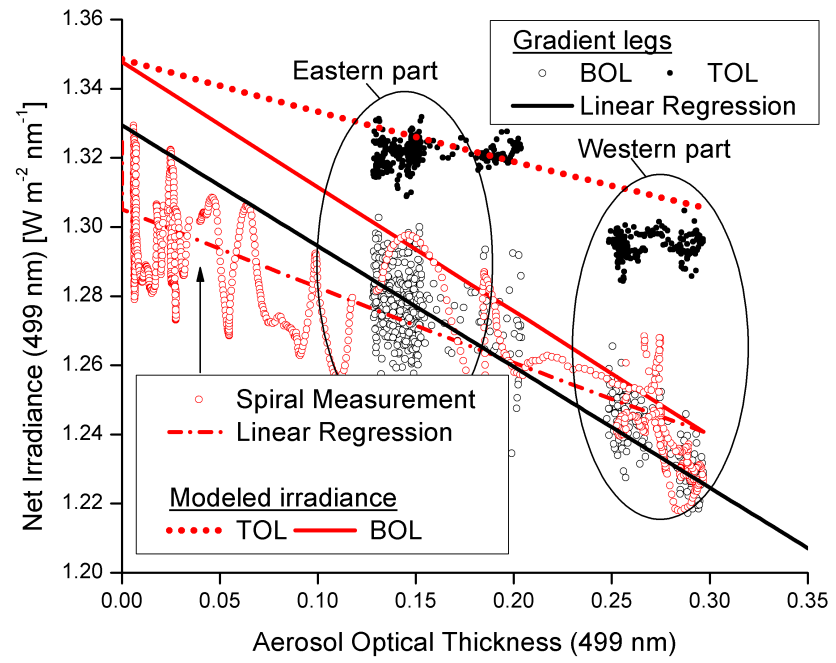

Fig. 3. Net irradiance $(499 \mathrm{~nm})$ versus AOT $(499 \mathrm{~nm})$, for 13 March 2006 (case over ocean). Black symbols and lines illustrate the gradient method: Measurements below the aerosol gradient (BOL) are shown as open circles and closed circles above (TOL); the regression line is derived from data of both portions of a leg (Western and Eastern part) that is separated by a dissipating cloud in the middle. Spiral profile measurements are shown as red circles. The regression line (red dash-dotted line) is used to extrapolate irradiance pairs above and below the aerosol layer. These pairs are used in the iterative method to retrieve aerosol single scattering albedo and asymmetry parameter. The derived BOL and TOL forcing efficiencies are shown as slopes of the solid and dotted red lines.

the net irradiance is $1.31 \mathrm{~W} \mathrm{~m}^{-2} \mathrm{~nm}^{-1}$ - approximately the same value as seen on the high-level gradient leg at $\tau=0.29$. The irradiance pairs $\left\{F_{\text {top }}^{\uparrow}, F_{\text {top }}^{\downarrow}\right\}$ and $\left\{F_{\text {bot }}^{\uparrow}, F_{\text {bot }}^{\downarrow}\right\}$ are obtained by regressing the upward and downward irradiance against optical thickness in the same way as discussed above for net irradiance. From the regression lines $\left\{F^{\uparrow}(\tau), F^{\downarrow}(\tau)\right\}$ the TOL irradiance pair can be obtained at $\tau=\tau_{\text {top }}$, the BOL pair at $\tau=\tau_{\text {bot }}$. In Fig. 3, the individual attitude-corrected measurements (red circles) deviate from the regression line (red dash-dotted line) by about $\pm 2 \%$ which is caused by residuals in the attitude correction that cannot be accounted for. This is the basis for the empirical error given in Sect. 2.3. The error in the slope of the linear regression also provides estimates of the uncertainty of the BOL and TOL irradiance pair: $0.5 \%$ in this case.

In the next step, the publicly available radiative transfer model libRadtran (Mayer and Kylling, 2005; www. libradtran.org) with SBDART (Ricchiazzi, 1998) for atmospheric molecular absorption is used to calculate upward and downward irradiance above and below the layer for the specified wavelength and solar zenith angle. The profile of spectral aerosol extinction (one input parameter) is derived from the AATS-14 measurements within the layer, that is, between $\tau=\tau_{\text {top }}$ and $\tau=\tau_{\text {bot. }}$. A value of $\tau_{\text {top }}>0$ indicates an additional aerosol layer aloft which is included in the 


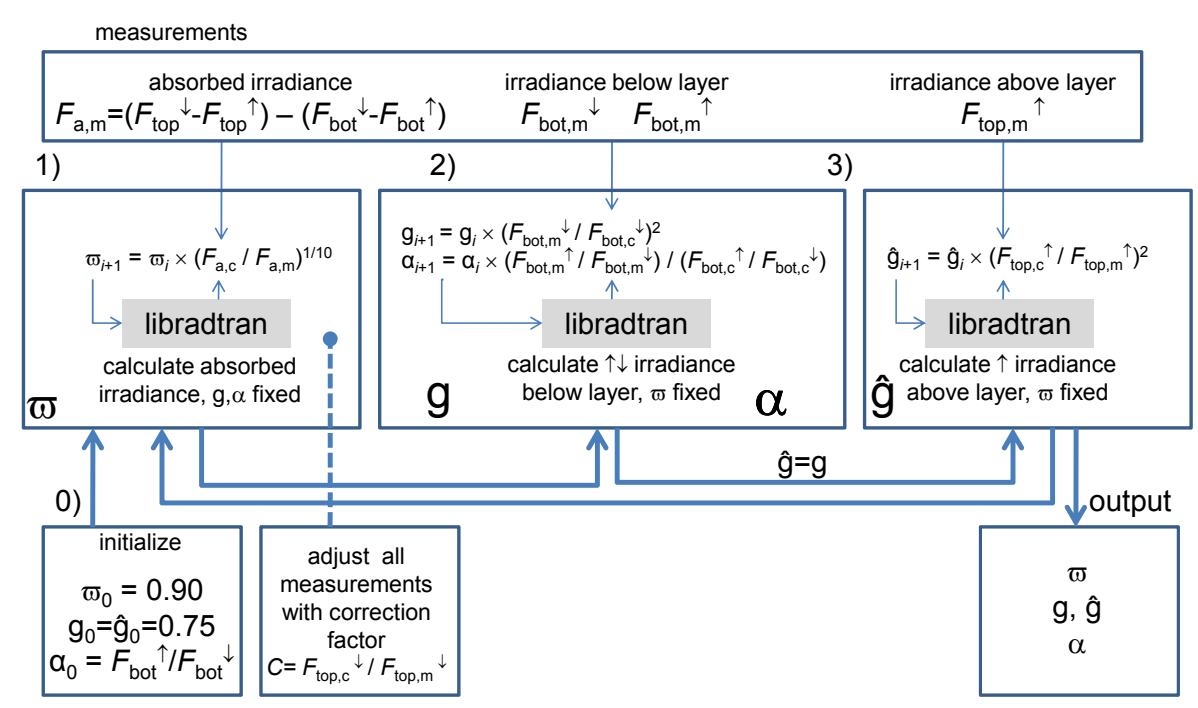

Fig. 4. Flowchart of the iterative algorithm for the retrieval of single scattering albedo, $\varpi$, asymmetry parameter, $g$ and $\hat{g}$, and surface albedo, $\alpha$, from the input irradiance pairs $\left\{F_{\text {bot }}^{\downarrow}, F_{\text {bot }}^{\uparrow}\right\}$ at the bottom and $\left\{F_{\text {top }}^{\downarrow}, F_{\text {top }}^{\uparrow}\right\}$ on top of the aerosol layer, using the libradtran radiative transfer model. The optical thickness between the top and bottom legs (not shown in the flowchart) is also required as input to libradtran. The iteration steps are labeled by index $i$.

profile above $\mathrm{Z}_{\mathrm{top}}$. The aerosol extinction below $\mathrm{Z}_{\mathrm{bot}}$ was determined either from the difference of the optical thickness retrieved at a nearby AERONET station and the value $\tau_{\text {bot }}$ from AATS-14 (as in Coddington et al., 2008), or by extrapolating the AATS-14 extinction profile within the layer down to the surface. Where available, extinction profiles from a High Spectral Resolution Lidar (HSRL, Hair et al., 2008) can be used in future applications. Additional model input such as atmospheric profiles (including relative humidity) was derived from the J-31 meteorological measurements. The extraterrestrial solar irradiance was taken from Kurucz (1992) at $1 \mathrm{~nm}$ spectral resolution. Figure 4 shows a flowchart of the algorithm where single scattering albedo, $\varpi$, asymmetry parameter, $g$, and surface albedo, $\alpha$, are iteratively adjusted until the modeled irradiance converges with the measured irradiance (index $i$ is incremented in each iteration step):

0. $i=0$ : Initialize the model with $\varpi_{0}=0.90, g_{0}=0.75$ and $\alpha_{0}=F_{\text {bot }}^{\uparrow} / F_{\text {bot }}^{\downarrow}$

1a. Run libradtran (loop \#1 : single scattering albedo $\varpi)$.

1b. Compare measured absorbed irradiance $F_{\text {abs, }}=\left(F_{\text {top }}^{\downarrow}-\right.$ $\left.F_{\text {top }}^{\uparrow}\right)-\left(F_{\text {bot }}^{\downarrow}-F_{\text {bot }}^{\uparrow}\right)$ with calculated values $F_{\text {abs, } c}$ and determine $\varpi$ for the next iteration step: $\varpi_{i+1}=\varpi_{i} \times$ $\left(F_{a b s, c} / F_{a b s, m}\right)^{1 / 10}$.

1c. Repeat steps $1 \mathrm{a}$ and $1 \mathrm{~b}$ until $F_{\mathrm{abs}, c} \approx F_{\mathrm{abs}, m}$ (within threshold $<0.1 \%$ ).

2a. Use the retrieved value for $\varpi$ from step 1 and run libradtran (loop \#2: asymmetry parameter $g$ and surface albedo $\alpha$ ). Rescale the measured irradiance pairs with factor $C$ (explained below) such that $F_{\text {top }, m}^{\downarrow}=F_{\text {top }, c}^{\downarrow}$.

2b. Compare measured and calculated downward irradiance below the layer: $F_{\mathrm{bot}, m}^{\downarrow}$ and $F_{\mathrm{bot}, c}^{\downarrow}$ and determine $\mathrm{g}$ for the next iteration step: $g_{i+1}=g_{i} \times\left(F_{\text {bot }, m}^{\downarrow} / F_{\text {bot }, c}^{\downarrow}\right)^{2}$.

2c. Adjust the surface albedo as follows: $\alpha_{i+1}=\alpha_{i} \times$ $\left(F_{\text {bot }, m}^{\uparrow} / F_{\text {bot }, m}^{\downarrow}\right) /\left(F_{\text {bot }, c}^{\uparrow} / F_{\text {bot }, c}^{\downarrow}\right)$.

2d. Repeat steps 2 a-c until $F_{\text {bot, } m}^{\downarrow} \approx F_{\text {bot, } c}^{\downarrow}$ (within threshold $<0.1 \%)$.

3. Using the reflected upward irradiance rather than the transmitted downward irradiance in step 2, retrieve a second value for the asymmetry parameter, denoted $\hat{g}$, while leaving the surface albedo and single scattering albedo constant. Use $\hat{g}_{i+1}=\hat{g}_{i} \times\left(F_{\mathrm{top}, c}^{\uparrow} / F_{\mathrm{top}, m}^{\uparrow}\right)^{2}$.

4. Repeat loops 1-3 until the values for $\varpi, g, \hat{g}$ and $\alpha$ are stable, that is, $\left|\varpi_{i+1}-\varpi_{i}\right|<0.001$ and $\left|g_{i+1}-g_{i}\right|<0.01$.

The exponents in $1 b(1 / 10)$ and $2 b(2)$ were chosen empirically to optimize convergence speed. They do not affect the result itself. The physical interpretation of $g$ and $\hat{g}$ is identical (first moment of the scattering phase function). Since the asymmetry parameter can be retrieved through transmitted $(g$, step \#2) or reflected irradiance $(\hat{g}$, step \#3), $g$ and $\hat{g}$ are technically regarded as independent retrievals (although $g$ from \#2 is used as initial value for $\hat{g}$ in \#3) that are compared afterwards. For a low order scattering atmosphere, $g$ is almost independent of $\alpha$. The opposite is true for $\hat{g}$ which can 
only be properly retrieved if the value for $\alpha$ is correct. The difference between $g$ and $\hat{g}$ is a measure of the retrieval consistency. The rescaling in step \#2a ensures that the modeled downward irradiance on top of the layer is consistent with the measurements. This is necessary because of uncertainties in the extraterrestrial irradiance. Rescaling all four irradiance components is equivalent to rescaling the extraterrestrial irradiance in the model. In this way, the irradiance values are effectively normalized with respect to $F_{\text {top }, c}^{\downarrow}$. In most cases, $C$ is close to unity. If the rescale factor $C$ falls outside the $5 \%$ range $(0.95<C<1.05)$, the retrieval failed (for example, due to undetected clouds that were not properly screened out). Furthermore, the retrieval is rejected if the difference between $g$ and $\hat{g}$ is larger than 0.05 , or if no convergence is reached after ten iterations.

The surface albedo adjustment in step \#2c is based on the calculated and modeled flight level albedo at $Z_{\text {bot }}$, following formula (1) in Coddington et al. (2008). It is important to note that the extinction profile and the single scattering albedo and asymmetry parameter below $Z_{\text {bot }}$ have an impact on the retrieved surface albedo. In absence of detailed knowledge about the aerosol properties below $\mathrm{Z}_{\mathrm{bot}}$, the retrieved surface albedo can be understood as effective surface albedo given the assumed aerosol properties. A poorly characterized aerosol below $Z_{\text {bot }}$ has no implications for the accuracy of the retrieved value of $\varpi$ and $g$ within the layer, nor on the derived forcing efficiency because the effective surface albedo is constrained by the measured irradiance at $\mathrm{Z}_{\text {bot }}$.

We found that the single scattering albedo part (step \#1) of the algorithm was far less sensitive to model-measurement disagreement in downward TOL irradiance than the asymmetry parameter (similar to Bergstrom et al., 2010). When turning off the rescale factor, $C$, the results for single scattering albedo were only slightly affected. However, the values for $g$ and $\hat{g}$ differed considerably, and sometimes no convergence was reached.

Figure 5 shows a two-dimensional retrieval plot of $g$ and $\varpi$, for five SSFR wavelengths (19 March 2006). The two small crosses within each circle represent the retrieved pairs of $\left\{\varpi_{0}, g_{0}\right\}$ and $\left\{\varpi_{0}, \hat{g}_{0}\right\}$ where the length of the cross bars spans the retrieval range resulting from the uncertainty in AOT. The retrieval range due to the AOT uncertainty, $\Delta \tau$, is simply calculated by running the retrievals with aerosol profiles that correspond to $\tau-\Delta \tau$ and $\tau+\Delta \tau$. At $1558 \mathrm{~nm}$, the retrieval is rejected because the values of $g$ and $\hat{g}$ are 0.05 apart. The circles indicate the boundaries within which

$\frac{\sqrt{\sum\left(F_{k}(\varpi, g)-F_{k}\left(\varpi_{0}, g_{0}\right)\right)^{2}}}{F_{\text {top }}^{\downarrow}}<0.01$,

where $F_{k}$ are $F_{\text {top }}^{\uparrow}, F_{\text {bot }}^{\uparrow}$ and $F_{\text {bot }}^{\downarrow}$. The large thin error bars reflect the associated range in retrieved single scattering albedo and asymmetry parameter. It should be noted that in the

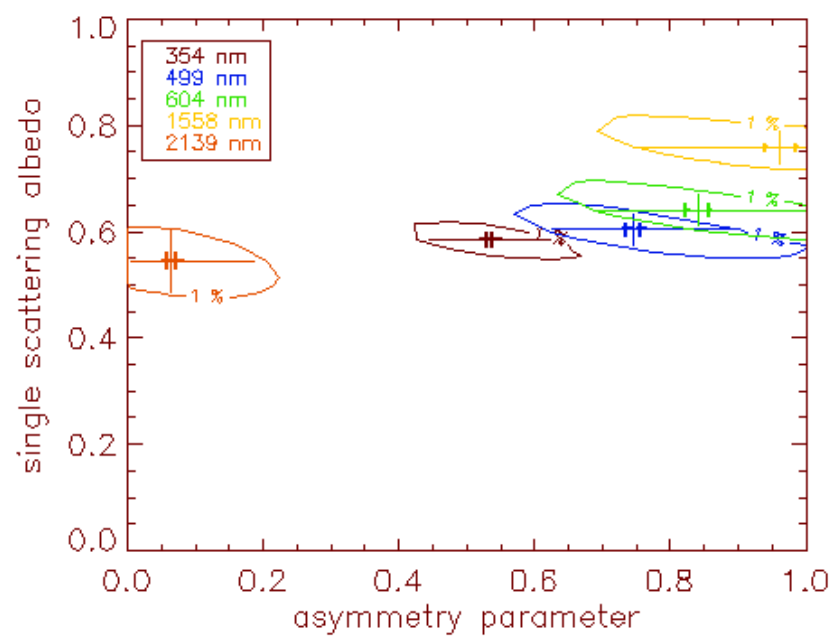

Fig. 5. Two-dimensional retrieval plot of asymmetry parameter $g$ and $\hat{g}$, and single scattering albedo $\varpi$, for five SSFR wavelengths (19 March 2006). The two small crosses within each circle represent the retrieved pairs of $\left\{\varpi_{0}, g_{0}\right\}$ and $\left\{\varpi_{0}, \hat{g}_{0}\right\}$ where the length of the bars spans the retrieval range that is introduced by the uncertainty in AOT. The circles indicate the boundaries within which the root mean square of $F_{k}(\varpi, g)-F_{k}\left(\varpi_{0}, g_{0}\right)$ is below $1 \%$ of $F_{1}^{\downarrow}$, where $F_{k}$ are $F_{1}^{\uparrow}, F_{0}^{\uparrow}$ and $F_{0}^{\downarrow}$; the large thin error bars reflect the associated range in retrieved single scattering albedo and asymmetry parameter.

residual formula above, identical weight is given to the three irradiance components. In lieu of a more rigorous error propagation analysis for the new algorithm, we use this root mean square method for testing the sensitivity of the retrievals to the input parameters. Since the irradiance components effectively enter the algorithm relative to the value of $F_{\text {top }}^{\downarrow}$, the absolute radiometric uncertainty is irrelevant for error propagation. The irradiance error is between $0.5 \%$ (uncertainty of extrapolated irradiance pairs from spiral measurement, illustrated in Fig. 3) for spiral measurements and 2\% for flux divergence measurements (accuracy of attitude correction). For Fig. 5 and throughout the remainder of this manuscript, we chose $1 \%$ accuracy for defining the circle boundaries and error bars. Apart from the different errors (2\% and $0.5 \%)$ associated with flux divergence and spiral (profile) measurements, the retrieval technique is identical.

The shape of the residual plots shows that the single scattering albedo is better constrained than asymmetry parameter. The value of $\varpi_{0}$ is only weakly dependent on $g_{0}$. For example, $\varpi_{0}$ varies from 0.63 to 0.55 for $g_{0}=0.57 \ldots 0.95$ (at $499 \mathrm{~nm})$. In Bergstrom et al. (2007, 2010), only absorbed irradiance is used for the retrieval of $\varpi_{0}$, and the result is almost independent of the choice of $g$. For the new algorithm presented here, the sensitivity to $g$ (although weak) is desired and comes from the separate use of $F^{\downarrow}$ and $F^{\uparrow}$ in the algorithm. 


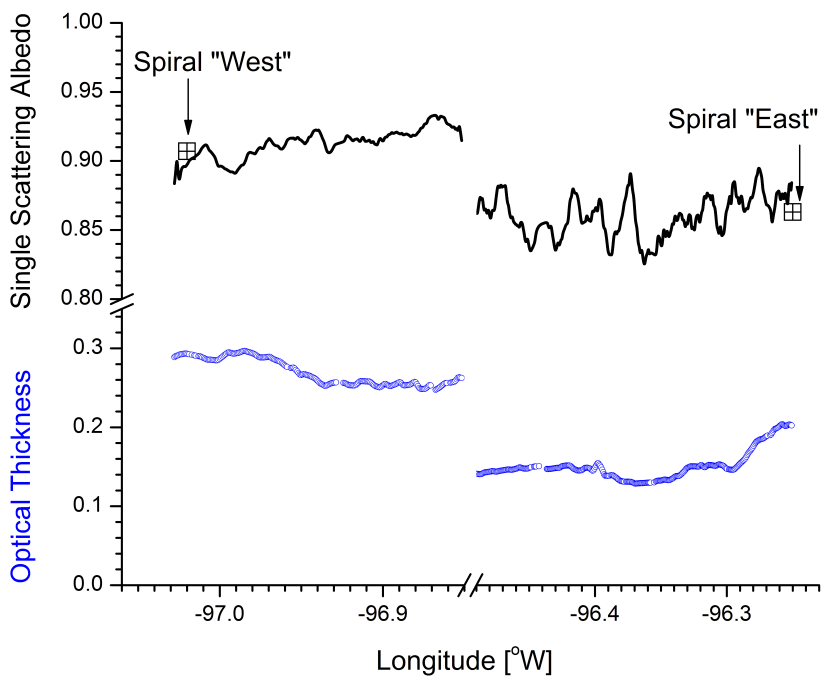

Fig. 6. Single scattering albedo (black) and optical thickness (blue) at $499 \mathrm{~nm}$ for the flux divergence leg from the case over sea (13 March 2006). Single scattering albedo is derived from individual points along the flux divergence leg (line) and within two spirals ("East" and "West", symbols).

The retrieved $\varpi, g$ and $\alpha$ are used to derive the TOL and BOL radiative forcing efficiencies: First, the net irradiances on top and at the bottom of the layer are calculated for a set of values of $\tau$, ranging from $\tau=0$ (clear-sky, unperturbed conditions) to $\tau=\tau_{\text {bot }}$ (perturbed condition). The forcing efficiency is obtained from the slope of the regression line as in the gradient method, or simply from the ratio $\left(F_{\text {net }}\left(\tau_{\text {bot }}\right)-\right.$ $\left.F_{\text {net }}(0)\right) / \tau_{\text {bot }}$. In cases where the aerosol layer extends below the low-level leg (often the case in the Mexico City area), the value of $\tau_{\text {bot }}$ does not represent the entire layer, and the derived TOL and BOL aerosol forcing is less than when using the total column-integrated value for $\tau$ as available from AERONET. However, the forcing efficiency is an intensive quantity (forcing normalized by optical thickness) and is therefore not sensitive to any particular choice of $Z_{b o t}$ or vertical extent of the probed aerosol layer.

For the spiral in Fig. 3, the solid and dotted red lines represent the calculated net irradiances. Their slopes are the BOL and TOL forcing efficiencies, respectively. The modeled BOL forcing efficiency is similar to its directly measured counterpart (i.e., the slope of the solid red line is similar to that of the black line). The offset between the lines is below $2 \%$, which is consistent with the attitude correction errors.

\section{Results}

Instantaneous forcing efficiencies are given by the slopes of the solid (BOL) and dotted (TOL) lines in Fig. 3. Table 1 gives a complete overview of forcing efficiencies, single scat-

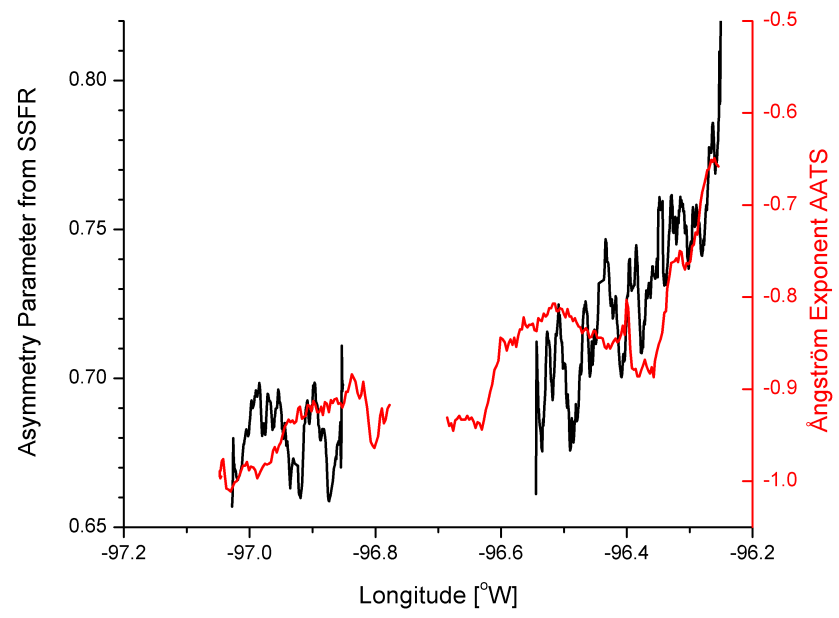

Fig. 7. Asymmetry parameter (black) from SSFR and Ångström exponent (red) from AATS-14 for the same case as Fig. 6, both at $499 \mathrm{~nm}$.

tering albedo, asymmetry parameter, and surface albedo for $499 \mathrm{~nm}$ on 13 (ocean case) and 19 March 2006 (land case). For the ocean case, irradiance spectra from the eastern flux divergence leg at $96.26^{\circ} \mathrm{W}$ were chosen, and $\varpi, g, \hat{g}$, and $\alpha$ were retrieved with the new method. Nearby $\left(96.20^{\circ} \mathrm{W}\right)$, measurements during a spiral profile were used. The retrieved values for $\varpi$ and $g$, as well as forcing efficiency are nearly identical (Table 1). This shows that the new method provides the same results, regardless of whether the required irradiance pairs below and above the layer are taken from collocated horizontal legs or from a vertical profile (Fig. 1). From the measurements on the western flux divergence leg, a pair of measurements was picked at $97.20^{\circ} \mathrm{W}$. A spiral was also flown at $97.20^{\circ} \mathrm{W}$, yielding slightly higher results for $\varpi$

The BOL relative forcing efficiencies $e$ derived from the spirals and flux divergence legs range from $-24 \%$ to $-28 \%$ on the eastern and the western leg; a value of $-20 \%$ was derived from the gradient method. The TOL relative forcing efficiencies range from $-9 \%$ to $-5 \%$ (west to east). The directly measured TOL forcing efficiency (about $0 \%$ ) is unphysical because the two underlying air masses have different properties: The single scattering albedo in the west is 0.90 , as opposed to 0.86 (more absorbing) in the east; the asymmetry parameter is 0.68 in the west, as opposed to 0.76 in the east (larger particles).

Since the pairs of irradiance are available along the entire flux divergence leg, the retrievals can be done for each individual point along the leg. Figure 6 shows the single scattering albedo (black) and optical thickness (blue) as a function of longitude. The single scattering albedo varies from around 0.90 to 0.86 for the western and eastern legs, which is in agreement with the results obtained from the two spirals. The error in $\varpi$ (not shown) is composed of the two contributions discussed in Sect. 2.4.2. It increased from \pm 0.02 in 
Table 1. Aerosol optical properties and BOL/TOL forcing efficiencies from SSFR gradient legs (direct measurement) and measurement/model approach for the cases on 13 and 19 March (over ocean and over land), at $499 \mathrm{~nm}$. No $\varpi$ and $g$ values were retrieved from the direct forcing measurements (gradient legs). Instead, the ranges of optical thickness $\Delta \tau$ and length $\Delta x$ in kilometers are indicated. For measurements over land, AERONET retrievals of $\varpi$ and $g$, as well as the derived surface albedo value $\alpha$ are shown, and the measurements are arranged from south to north (increasing distance from the source) going down the table.

\begin{tabular}{|c|c|c|c|c|c|}
\hline \multirow[t]{2}{*}{13 March 2006 (ocean) } & \multirow[t]{2}{*}{ optical properties } & \multicolumn{2}{|c|}{$E\left[\mathrm{~W} \mathrm{~m}{ }^{-2} \mathrm{~nm}^{-1} / \tau_{499}\right]$} & \multicolumn{2}{|c|}{$e\left[\% / \tau_{499}\right]$} \\
\hline & & BOL & TOL & BOL & TOL \\
\hline $\begin{array}{l}96.26^{\circ} \mathrm{W} \text { flux divergence } \\
96.20^{\circ} \mathrm{W} \text { spiral } \\
97.20^{\circ} \mathrm{W} \text { flux divergence } \\
97.20^{\circ} \mathrm{W} \text { spiral } \\
\text { gradient leg }\end{array}$ & $\begin{array}{l}\varpi=0.865 \pm 0.038, g=0.75 \pm 0.09 \\
\varpi=0.863 \pm 0.038, g=0.78 \pm 0.09 \\
\varpi=0.897 \pm 0.021, g=0.68 \pm 0.06 \\
\varpi=0.905 \pm 0.021, g=0.67 \pm 0.06 \\
\Delta \tau=0.2, \Delta x=93 \mathrm{~km}\end{array}$ & $\begin{array}{l}-0.40 \\
-0.36 \\
-0.37 \\
-0.32 \\
-0.35\end{array}$ & $\begin{array}{l}-0.09 \\
-0.06 \\
-0.13 \\
-0.08 \\
-0.00\end{array}$ & $\begin{array}{l}-27 \pm 8 \\
-28 \pm 9 \\
-25 \pm 5 \\
-24 \pm 5 \\
-20 \pm 1\end{array}$ & $\begin{array}{l}-8 \pm 4 \\
-4 \pm 4 \\
-9 \pm 3 \\
-9 \pm 3 \\
0 \pm 8\end{array}$ \\
\hline \multicolumn{6}{|l|}{19 March 2006 (land) } \\
\hline $\begin{array}{l}\text { T0 } 19.48^{\circ} \mathrm{N} \text { ramp } \\
\text { T0 gradient leg } \\
\text { T0 AERONET, } 19.48^{\circ} \mathrm{N} \\
19.860^{\circ} \mathrm{N} \text { flux divergence } \\
19.885^{\circ} \mathrm{N} \text { flux div. }(\sim \mathrm{T} 1) \\
19.915^{\circ} \mathrm{N} \text { flux div. }(\sim \mathrm{T} 2) \\
\mathrm{T} 220.01^{\circ} \mathrm{N} \text { spiral } \\
\mathrm{T} 1 / \mathrm{T} 2 \text { gradient leg }\end{array}$ & $\begin{array}{l}\varpi=0.610 \pm 0.055, g=0.71 \pm 0.15, \alpha=0.11 \\
\Delta \tau=0.1, \Delta x=8 \mathrm{~km} \\
\varpi=0.747, g=0.76 \\
\varpi=0.871 \pm 0.023, g=0.66 \pm 0.08, \alpha=0.13 \\
\varpi=0.839 \pm 0.025, g=0.60 \pm 0.08, \alpha=0.12 \\
\varpi=0.879 \pm 0.038, g=0.59 \pm 0.09, \alpha=0.11 \\
\varpi=0.917 \pm 0.020, g=0.72 \pm 0.09, \alpha=0.08 \\
\Delta \tau=0.3, \Delta x=20 \mathrm{~km}\end{array}$ & $\begin{array}{l}-0.918 \\
-0.63 \\
-0.360 \\
-0.457 \\
-0.384 \\
-0.530 \\
-0.649\end{array}$ & $\begin{array}{l}-0.253 \\
\text { n.a. } \\
-0.054 \\
-0.080 \\
-0.105 \\
-0.157 \\
-0.172\end{array}$ & $\begin{array}{l}-65 \pm 11 \\
-43 \pm 10 \\
\quad \text { n.a } \\
-23 \pm 4 \\
-27 \pm 4 \\
-25 \pm 7 \\
-33 \pm 10 \\
-46 \pm 4\end{array}$ & $\begin{array}{l}-16 \pm 5 \\
\text { n.a. } \\
-3 \pm 3 \\
-5 \pm 3 \\
-8 \pm 4 \\
-10 \pm 7 \\
-12 \pm 9\end{array}$ \\
\hline
\end{tabular}

the west to \pm 0.06 in the east. This increase is related to the lower optical thickness on the eastern leg: A decreasing AOT generally decreases the sensitivity of the retrieval.

Figure 7 shows the asymmetry parameter for the same leg as in Fig. 6. It increases towards the east, indicating more forward scattering and thus larger particles. A related quantity, the Ångström exponent as derived from the AATS-14 wavelength-dependence of optical thickness, is also shown (red), suggesting a similar trend with respect to the aerosol size distribution. The SSFR-derived asymmetry parameter has an uncertainty of 0.06 in the west and up to 0.15 in the east (not shown), again due to the different AOT. In the east, the uncertainty is as large as the increase in $g$ itself. The highest uncertainty values $(0.15)$ occur below a mid-visible AOT of 0.15 , which can be regarded as the lower limit of AOT required for a successful $g$ retrieval.

Figure 8 shows an overview of spectral relative forcing efficiency, single scattering albedo, and asymmetry parameter (from top to bottom), for two cases over ocean (left) and two cases over land (right). AERONET retrievals of $\varpi$ and $g$, insitu measurements of $\varpi$, and Mie calculations for $g$ are only shown for the land cases. T0, T1, and T2 denote the ground stations in (T0, near the airport) and around (T1, T2) Mexico City (see Figure $2 b$ for exact locations). The mid-visible wavelength of $499 \mathrm{~nm}$ (used in Figs. 3, 6, 7 and Table 1) is marked with a dashed line. For more clarity, error bars are sometimes omitted.

The 19 March case (in right-hand panel) was used to check the consistency of the results from the new method with the direct measurement of forcing efficiency over land. The thick black and magenta lines in Fig. 8b show the BOL relative forcing efficiency as derived from the gradient method. The leg labeled T1/T2 (black line) was located between T1 and T2. It was traced back at higher altitude along an almost identical ground track. Along these collocated flux divergence legs, three irradiance pairs were picked at $19.860^{\circ} \mathrm{N}$, $19.885^{\circ} \mathrm{N}$, and $19.915^{\circ} \mathrm{N}$, and the local forcing efficiencies were calculated via the retrieval of $\varpi$ and $g$. In addition, a spiral near $\mathrm{T} 2$ was used $\left(20.01^{\circ} \mathrm{N}\right)$. Detailed results for $499 \mathrm{~nm}$ are shown in Table 1. While the calculated BOL relative forcing efficiencies are mutually consistent (around $25-35 \%)$, the directly measured value in the T1/T2 area is substantially higher $(46 \%)$. This mismatch is probably due to the gradient in surface albedo $(0.11$ to 0.13 at $499 \mathrm{~nm})$ that occurred over the T1/T2 gradient leg. This $17 \%$ change introduces a bias in the regression line, and the slope no longer reflects forcing efficiency alone. For this reason, the gradient method is inappropriate here.

The disagreement between directly measured forcing efficiency (from the gradient method) and modeled forcing efficiency (from the new method) occurs across the entire spectrum. In Fig. 8b, the T1/T2 gradient forcing efficiency (thick black line, labeled "BOL T1/T2") is larger in magnitude than the flux divergence retrieval results north of $\mathrm{T} 1$ (thin black line, labeled " T1", at $19.885^{\circ} \mathrm{N}$ ), near T2 (blue line, labeled " $\sim \mathrm{T} 2$ ", at $\left.19.915^{\circ} \mathrm{N}\right)$, and the spiral results at T2 (green line, labeled "T2", at $20.01^{\circ} \mathrm{N}$ ). Another gradient leg was flown near T0 (magenta line, labeled "BOL T0"), 


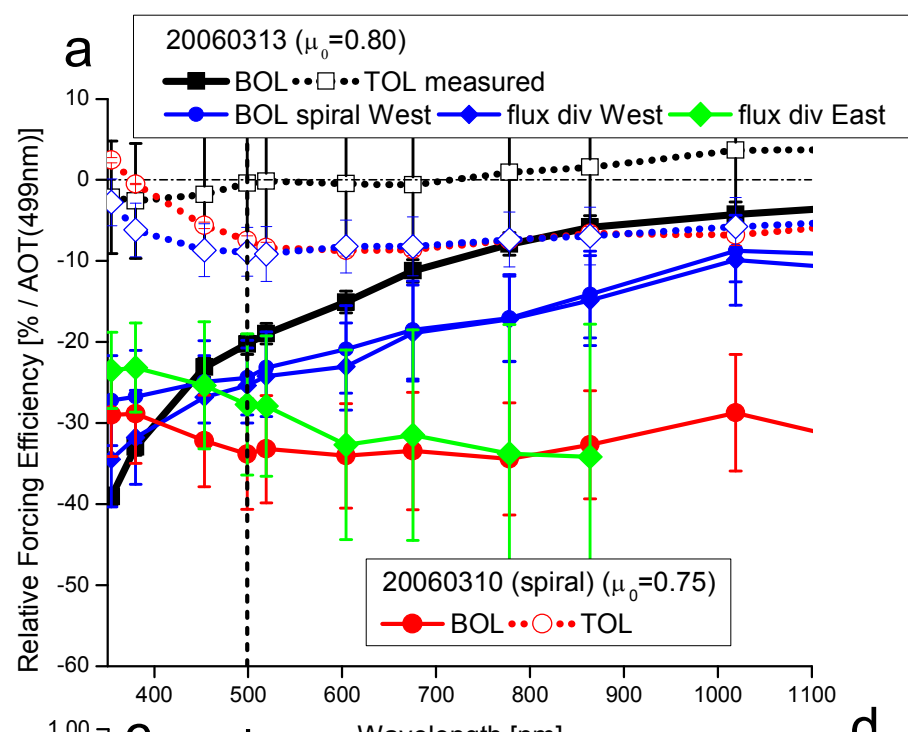

b
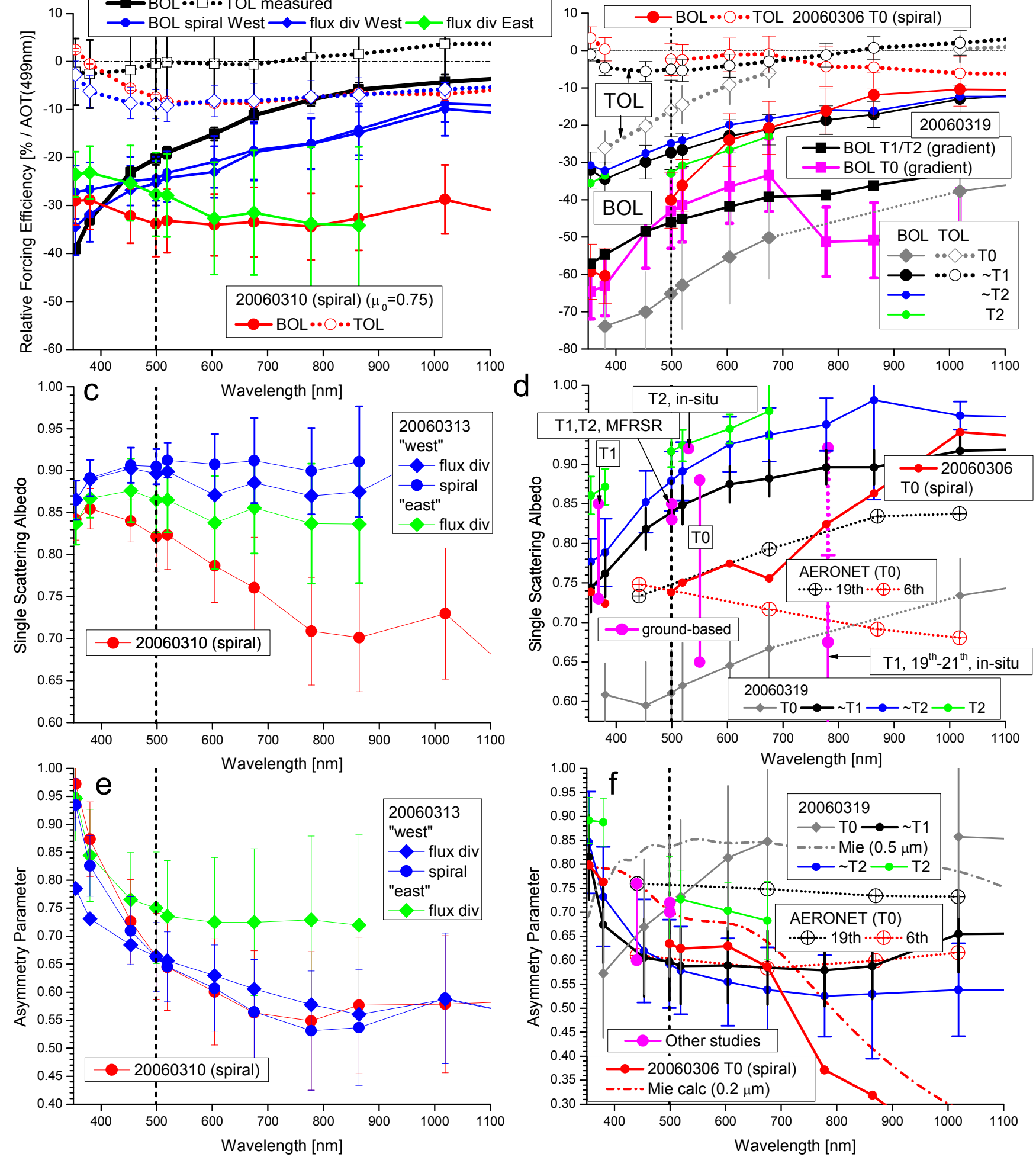

Fig. 8. Overview of relative spectral forcing efficiency, single scattering albedo, and asymmetry parameter (from top to bottom), over ocean (left: 10 and 13 March 2006) and over land (right: 6 and 19 March 2006). AERONET retrievals, in-situ measurements (of single scattering albedo), and Mie calculations (for asymmetry parameter) are only shown for the land cases. T0, T1, and T2 denote the ground stations in and around Mexico City. The mid-visible wavelength of $499 \mathrm{~nm}$ (used in Figs. 3, 6, 7 and Table 1) is marked with a dashed line. 
complemented by a descent into the aerosol layer in the same area (gray line, labeled "T0"). The latter was used for $\{\varpi$, $g$ \} retrievals in the same way as the spirals. In this case, the directly measured forcing efficiency (T0 gradient, magenta) is smaller in magnitude than the modeled values (T0 descent, gray) up to a wavelength of $700 \mathrm{~nm}$, and larger above. The cross-over is an artifact related to the increase of the surface albedo between 700 and $750 \mathrm{~nm}$ (see Fig. 9b, black line). In addition, the directly measured forcing efficiency spectrum depends on the choice of the length of the gradient leg. The two factors together are indicative of a bias due to heterogeneous surface albedo.

The spectral single scattering albedo and asymmetry parameter associated with the forcing efficiencies in Fig. 8b are shown in Fig. 8d and f. For selected cases, the TOL forcing efficiencies were added to Fig. $8 \mathrm{~b}$ (dotted lines). The extreme BOL forcing efficiency of $65 \%$ at $499 \mathrm{~nm}$ near T0 can be traced back to an extremely low value of $\varpi \approx 0.6-$ as opposed to 0.74 to 0.91 for the other sites. Selected groundbased observations are shown in magenta:

- $368 \mathrm{~nm}$ : range of $\varpi$ throughout March 2006 at T1, from Corr et al. (2009)

- 500 nm: Multi-Filter Rotating Shadowband Radiometer (MFRSR) $\varpi$ retrievals at T1 and T2, from Doran et al. (2007) based on an algorithm by Kassianov et al. (2007)

- $530 \mathrm{~nm}$ : in-situ measurements with a nephelometer and a PSAP on 19 March 2006 at T2, from Doran et al. (2007)

- 532 nm: T0 in-situ measurements on 19 March 2006, from Marley et al. (2009)

- $781 \mathrm{~nm}$ : in-situ measurements at T1, measured with the integrated photoacoustic/nephelometer (Arnott et al., 1999) onboard the Aerodyne Mobile Laboratory van at T1. The error bar indicates mean \pm standard deviation; the dotted line extends to the maximum.

Concerning the range of single scattering values, ParedesMiranda et al. (2009) and Corr et al. (2009) show that there is a strong diurnal pattern, where minima in $\varpi$ occur at different times of the day depending on the site and altitude. This makes a direct intercomparison difficult.

The spectral shape of the asymmetry parameter (Fig. 8f) stands out for the spiral at T0 (19 March in gray). In all other examples, including those from above the sea (Figure 8e) and another spiral over T0 on a different day (6 March, red line in Fig. 8f), $g$ decreases with wavelength. An increase with wavelength is atypical. However, this behavior is not necessarily an artifact. Mie calculations show that for spheres with $0.5 \mu \mathrm{m}$ radius (gray dash-dotted line, Fig. 8f), the asymmetry parameter does increase up to $500 \mathrm{~nm}$. In contrast, the aerosol particles that prevailed around T0 on 6 March (red line) appear to be smaller: In this case, the spectral shape of $g$ (decreasing with wavelength) is approximated by Mie calculations for $0.2 \mu \mathrm{m}$ radius particles (red dash-dotted line). Results from other studies are shown in magenta: a range of AERONET-retrieved $g(440 \mathrm{~nm})$ at $\mathrm{T} 0$ for the entire month (Corr et al., (2009) and a MFRSR-retrieved range of $g$ for five days during March near T0 (Barnard et al., 2008). The AERONET retrievals of $g$ from T0 are shown in black (19 March) and red (6 March).

Generally, due to the limited data set acquired by the J-31, we cannot unambiguously detect an evolution of $\varpi$ and $g$ from the source(s) downwind to the outflow regions. Rather, the measurements on the 19 March and other days most likely occur in areas where the pollution has a variegated origin. For example, as shown in Table 1, the single scattering albedo increases from south (T0) to north (T2), as expected for the urban outflow air mass, but drops back to lower values in between those sites (e.g., at $19.885^{\circ} \mathrm{N}$ ), probably because younger plumes are intercepted on the way. Under these conditions, it is hard to compare airborne retrievals with ground-based measurements. It is also unsurprising that the agreement with AERONET retrievals from the site at T0 for 6 and 19 March 2006 is poor (for single scattering albedo and asymmetry parameter), since the sampling volumes and times are different.

Given the large variability in $\varpi$ and $g$, it is surprising that the magnitude and spectral shape of the relative forcing efficiencies are quite similar over ocean (Fig. 8a) and land (Fig. 8b). When excluding T0 measurements, the "campaign-average" relative forcing efficiencies range from $-30 \%$ at $400 \mathrm{~nm}$ to $-10 \%$ at $1000 \mathrm{~nm}$ at BOL, very similar to measurements by Redemann et al. (2006) for INTEXNA (Intercontinental chemical Transport Experiment - North America). The TOL forcing efficiencies vary between $-10 \%$ (slightly cooling) and $0 \%$ (no radiative effect) across the spectrum. Exceptions are the air masses over ocean that were measured on the eastern part of the flux divergence leg on $13 \mathrm{March}$, and the one on $10 \mathrm{March}$, with a value of about $-30 \%$. The reason for the deviation from the other cases lies in the single scattering albedo for 10 March and asymmetry parameter for 13 March (see Fig. 8c and e). Possibly, this different behavior is associated with a humidified aerosol with large particle size. This explanation is supported by the Ångström parameter (Fig. 7) which decreases in magnitude from west to east, along with an increase in asymmetry parameter. Differences between individual forcing efficiency spectra occur mainly in the near-UV. This is mainly caused by the strong UV absorption of black and organic carbon (see Bergstrom et al., 2010).

\section{Surface albedo measurements}

As discussed earlier, the retrieval of $g$ and (to a smaller degree) $\varpi$ depends on the underlying spectral surface albedo. 

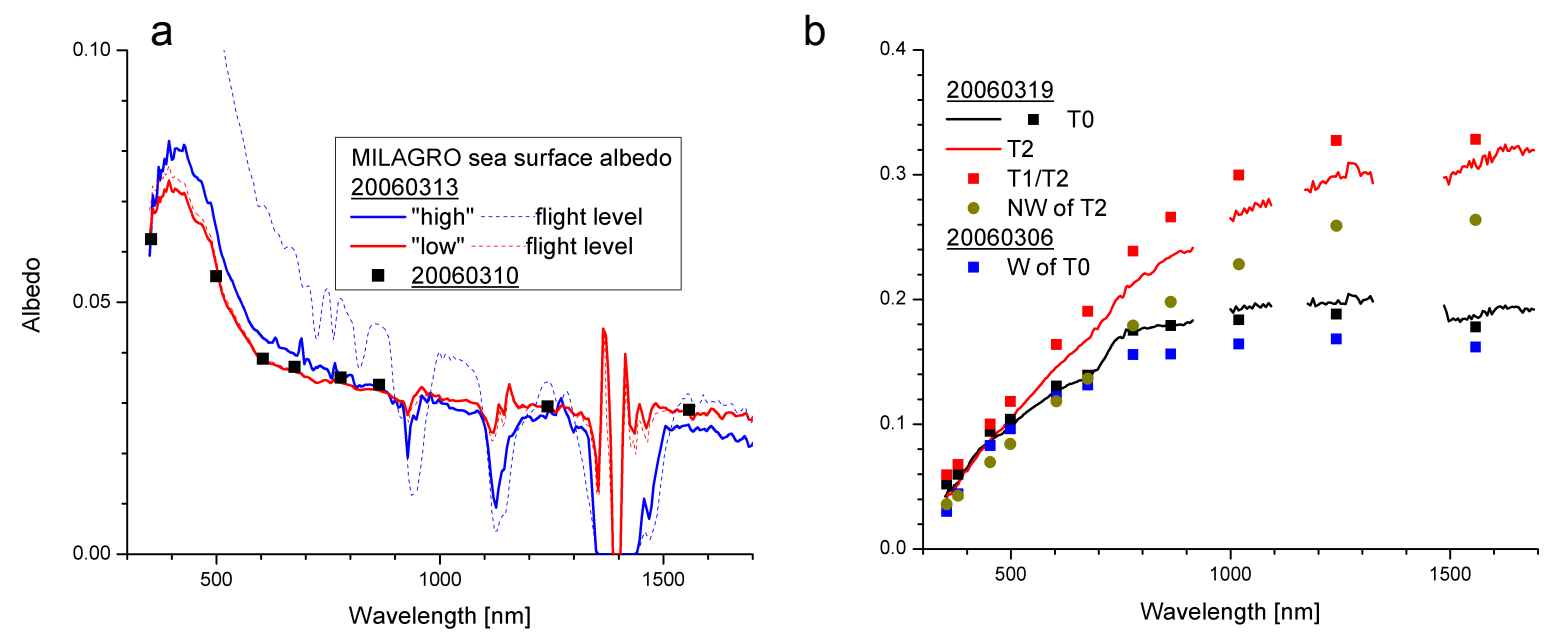

Fig. 9. Surface albedo retrievals over ocean (a) and land (b). The dotted lines in (a) show the flight level albedo, the solid lines the spectra corrected for the effects of the atmosphere for a high-level leg (blue) and a low-level leg (red). The black dots stem from the new retrieval algorithm for 10 March. In (b), the lines show the atmospherically corrected results using the algorithm by Coddington et al. (2008); the symbols show the results from the new algorithm at nearby locations.

Also, the forcing efficiency is a function of surface albedo (Russell et al., 2002; Bierwirth et al., 2009). We therefore show some typical surface albedo results from the MILAGRO experiment. Detailed comparisons of along-flighttrack surface albedo with satellite-derived values and surface data are given by Coddington et al. (2008). The original correction technique including aerosols was first introduced by Wendisch et al. (2004). The challenge in deriving surface albedo from aircraft or satellite measurements lies in the atmospheric correction where albedo at flight-level is converted into the values at the surface. The correction for the molecular scattering in the layer between the surface and the aircraft is straightforward. However, in the presence of an aerosol layer with unknown optical properties and spatial heterogeneity, the atmospheric correction is difficult. Further problems arise within atmospheric absorption bands, especially because the concentration of water vapor, the strongest gas absorber in the solar wavelength range, is typically poorly known. In our new approach as described in Sect. 2.4.2, the surface albedo is a "by-product" of the retrieval of $\varpi$ and $g$. In Wendisch et al. (2004) and Coddington et al. (2008), the aerosol properties were taken from AERONET retrievals or in-situ measurements. Here, all values are retrieved simultaneously. However, the new method can only be used at locations where pairs of above- and below (or in-) layer measurements of irradiance are available, like in spirals or flux divergence legs. For the retrieval of surface albedo along an entire flight leg at one level such as in Coddington et al. (2008), the new method can therefore not be used. Another limitation is that if the aerosol properties below the low-level leg are unknown, assumptions have to be made. In some cases, optical thickness or even single scattering albedo and asymmetry parameter can be obtained from ground-based observations. If those are unavailable, the extinction profile from AATS-14 is usually extrapolated to the ground, and the single scattering albedo and asymmetry parameter retrieved within the layer are also used for the layer between the surface and the lowest flight leg. Under these circumstances, the resulting surface albedo should be called "effective surface albedo", given the assumed aerosol properties of the lowest aerosol layer. The choice of aerosol properties below the lowest flight leg and thus the effective surface albedo have only minor consequences for the derived forcing efficiency since the BOL irradiance pair constrains $F_{\text {net }}\left(\tau_{\text {bot }}\right)$. To first order, it is sufficient to know the effective surface albedo for the calculation of the clearsky value $F_{\text {net }}(0)$. Coddington et al. (2008) performed tests that showed the sensitivity of the retrieved surface albedo to single scattering albedo, asymmetry parameter, and optical thickness below the aircraft. They are not reproduced here because they are only of minor relevance for the forcing efficiency calculations.

Figure 9 shows selected results of surface albedo over ocean (a) and land (b). The lines show the spectral surface albedo from the method of Coddington et al. (2008); the points show the results of the new method at some of the AATS-14 wavelengths. The dotted lines in Fig. 9a show the flight level albedo. To test the algorithm of Coddington et al. (2008), data from a high and a low flight leg over the ocean were processed, resulting in similar sea surface albedo spectra (blue and red lines). The sea surface albedo for 10 March was determined using the new method. The negligible deviation in surface albedo on 13 March can be regarded as a measure of sea surface albedo variability.

Over land, the red and black lines show the retrieved surface albedo near $\mathrm{T} 2$ and $\mathrm{T} 0$ from the method by Coddington 
et al. (2008), where aerosol properties from AERONET were used for the atmospheric correction. The new method was applied for data from 19 March 2006, the aforementioned spiral near T2 and the descent near T0 (red and black symbols). For T0, close agreement with the Coddington et al. (2008) results is observed. The results from 6 March 2006 west of T0 are also shown (blue symbols). A sensitivity analysis of retrieved surface albedo to aerosol properties (single scattering albedo, asymmetry parameter, and optical thickness) is presented in Coddington et al. (2008). In the T2 area, the surface albedo heterogeneity is larger than around $\mathrm{T} 0$. The range is indicated by plotting spectra from the neighborhood of T2 (19 March 2006): from an area between T1 and T2 (red symbols), and from a location northwest of $\mathrm{T} 2$ (green symbols). The variability is about $\pm 15 \%$, which means that, as noted before, the gradient technique for forcing efficiency is not possible in this area.

\section{Conclusions}

We introduced a new method that allows for the simultaneous retrieval of aerosol single scattering albedo $\varpi$, asymmetry parameter $g$, and surface albedo $\alpha$, and for deriving measurement-constrained aerosol forcing efficiencies on top and at the bottom of an aerosol layer (TOL and BOL) from airborne aerosol optical thickness and irradiance measurements. This method is useful when a measurement of the forcing efficiency with the gradient method (Redemann et al., 2006) is impractical because (a) the gradient of AOT is too weak, (b) the underlying surface heterogeneity introduces a bias in measured upwelling and net irradiance, (c) the aerosol optical properties $(\varpi, g)$ change during the flight leg, or (d) the solar zenith angle changes too much during the flight leg. In contrast to the gradient method, the new approach can be used to measure aerosol properties at specific locations provided that pairs of irradiance above and below the layer are available. In this way, measured vertical profiles of irradiance and AOT allow for deriving forcing and aerosol optical properties even in the absence of a horizontal gradient in AOT. The spiral measurements minimize the error induced by surface albedo heterogeneity on the local forcing efficiency. The new method was tested for two cases over land and two cases over ocean. It gave consistent results for single scattering albedo, asymmetry parameter and forcing efficiencies, no matter where the required irradiance pairs were extracted: from vertically stacked legs (flux divergence legs), spirals, or ramps. We also showed that the aerosol single scattering albedo and asymmetry parameter, as retrieved point-by-point along a flux divergence leg over ocean, varied considerably. Both AATS-14 measurements of Ångström exponent and SSFR retrievals of asymmetry parameter revealed the same trends with respect to the size distribution of the sampled aerosol.
Over land, the surface albedo heterogeneity biased the slopes of the regression line between net irradiance and aerosol optical thickness, and thus the gradient methodderived forcing efficiency. This is why the gradient method is traditionally only used over ocean. However, even over ocean, the AOT gradient-derived forcing efficiency agreed only marginally (within the limits of uncertainty) with that obtained from the new method. The reason is that the measurements occurred in two distinct air masses with different aerosol radiative properties. This prohibits using the gradient method where only AOT is allowed to change over some distance. Along-track retrievals of aerosol properties from the new method showed that single scattering albedo and asymmetry parameter were indeed different in each of the air masses.

The results of aerosol optical properties over land were compared with in-situ measurements and retrievals from AERONET and MFRSR. This proved to be challenging because of the extreme heterogeneity of the pollution in the Mexico City area. For example, on a northbound flight leg away from the City Center on 19 March 2006, the single scattering albedo generally increased. However, it dropped intermittently, probably when encountering a younger plume. Also, the asymmetry parameter did not generally increase further away from the source, as would be expected for growing particle size associated with water uptake in the course of aging. This leads to the conclusion that the flight track intercepted pollution of variegated origin. Horizontal and vertical heterogeneity might explain the disagreement between our retrievals and AERONET results at T0, for both single scattering albedo and asymmetry parameter. A further complication for direct intercomparison is the strong diurnal pattern in single scattering albedo (Paredes-Miranda et al., 2009).

The interpretation of spectral single scattering albedo and absorption aerosol optical thickness for MILAGRO is discussed in detail by Bergstrom et al. (2010) who present more cases over ocean and land. In contrast to the new method presented in this study, the Bergstrom algorithm (based on absorbed irradiance only) is not sensitive to (or affected by) the asymmetry parameter. Despite this difference, the $\varpi$ retrievals from both algorithms agree within the range of uncertainty. The largest differences occur at near-UV wavelengths, particularly over land where large aerosol absorption is encountered.

Surface albedo retrievals (a by-product, in addition to $\varpi$ and $g$ ) represent a further application of the algorithm. No significant differences were found to the retrievals by Coddington et al. (2008) and Wendisch et al. (2004) where the aerosol properties are prescribed. Considerable surface albedo heterogeneity occurred in the Mexico City urban region and in its rural surroundings.

The new method encountered problems when the aerosols were too inhomogeneous (for example in spirals where the aircraft intercepted a plume only on one side). For these cases, three-dimensional effects corrupt the retrieval that is 
based on one-dimensional radiative transfer. Usually, the convergence criteria set for the method were not met for these situations and the two different values for $g$ (from transmitted and reflected irradiance) did not coincide. A further difficulty that affects error analysis is the missing horizontal stabilization of the optical inlets of SSFR. This makes both aerosol measurements and error analysis difficult. Currently, a sizeable fraction of data has to be discarded due to the lack of such a platform for SSFR. For future aerosol missions, we are therefore planning to use stabilized platforms. Furthermore, we will examine three-dimensional effects for both heterogeneous aerosol layers and heterogeneous surface albedo. Since both influence the aerosol forcing efficiency, we are seeking to define an "effective" forcing efficiency that takes these heterogeneous conditions into account.

Generally, the spectral relative forcing efficiencies were surprisingly similar for almost all cases during MILAGRO, and to those encountered during INTEX-NA (Redemann et al., 2006): They ranged from $-30 \%$ at $400 \mathrm{~nm}$ to $-10 \%$ at $1000 \mathrm{~nm}$ at BOL, and between $-10 \%$ and $0 \%$ at TOL. Exceptions were measurements in extremely polluted areas near pollution sources and two air masses with large, humidified particles over the Gulf of Mexico. The largest forcing efficiency ranges were encountered at near-UV wavelengths. The remarkable similarity of the observations is in contrast with expectations, since the forcing efficiency is a function of surface albedo (e.g., Russell et al., 1997, 2002; Bierwirth et al., 2009). More data (for example, from snow-covered surfaces in the Arctic) will be examined to understand this phenomenon.

Acknowledgements. This work was financed by the NASA atmospheric radiation program (directed by Hal Maring). Sebastian Schmidt and Peter Pilewskie were supported by NASA grant NNX08AI83G, Robert Bergstrom by NNX08AH60. We thank John Pommier and Tony Trias, NASA Ames Research Center, for their technical support before and during the MILAGRO experiment, the crew of the J-31 aircraft, and for the support of the NASA ESPO team in Veracruz, Mexico. We also thank the staff of the AERONET stations in Tamihua (Mexico) and in the Mexico City urban area for maintaining the AERONET sites; the T0, T1, and T2 AERONET sites were established specifically for the MILAGRO experiment. The major part of this paper was written while the first author worked at the Meteorological Institute of the University for Natural Resources and Applied Life Sciences in Vienna, Austria. Thanks for the hospitality of P. Weihs, J. Wagner, and H. Kromp-Kolb.

Edited by: L. Molina

\section{References}

Arnott, W. P., Moosmüller, H., Rogers, C. F., Jin, T., and Bruch, R.: Photoacoustic spectrometer for measuring light absorption by aerosols: Instrument description, Atmos. Environ., 33, 28452852, 1999.

Bannehr, L. and Schwiesow, R.: A technique to account for the misalignment of pyranometers installed on aircraft, J. Atmos. Oceanic Technol., 10, 774-777, 1993.

Barnard, J. C., Volkamer, R., and Kassianov, E. I.: Estimation of the mass absorption cross section of the organic carbon component of aerosols in the Mexico City Metropolitan Area, Atmos. Chem. Phys., 8, 6665-6679, doi:10.5194/acp-8-6665-2008, 2008.

Bergstrom, R. W., Pilewskie, P., Russell, P. B., Redemann, J., Bond, T. C., Quinn, P. K., and Sierau, B.: Spectral absorption properties of atmospheric aerosols, Atmos. Chem. Phys., 7, 59375943, doi:10.5194/acp-7-5937-2007, 2007.

Bergstrom, R. W., Schmidt, K. S., Coddington, O., Pilewskie, P., Guan, H., Livingston, J. M., Redemann, J., and Russell, P. B.: Aerosol spectral absorption in the Mexico City area: results from airborne measurements during MILAGRO/INTEX B, Atmos. Chem. Phys., 10, 6333-6343, doi:10.5194/acp-10-63332010, 2010.

Bierwirth, E., Wendisch, W., Ehrlich, E., Heese, B., Tesche, M., Althausen, D., Schladitz, A., Müller, D., Otto, S., Trautmann, T., Dinter, T., Hoyningen-Huene, W., and Kahn, R.: Spectral surface albedo over Morocco and its impact on radiative forcing of Saharan dust, Tellus, 61B, 252-269, doi10.1111/j.16000889.2008.00395.x, 2009.

Bucholtz, A., Bluth, R. T., Kelly, B., Taylor, S., Batson, K., Sarto, A. W., Tooman, T. P., and McCoy Jr., R. F.: The Stabilized Radiometer Platform (STRAP) - An Actively Stabilized Horizontally Level Platform for Improved Aircraft Irradiance Measurements, J. Atmos. Oceanic Technol., 25, 2161-2175, 2008.

Chandrasekhar, S., Radiative transfer, Dover Publications Inc., New York, USA, 10-11, 1960.

Coakley, J. and Chylek, P.: The two-stream approximation in radiative transfer: Including the angle of the incident radition, J. Atmos. Sci., 32, 409-418, 1975.

Coddington, O., Schmidt, K. S., Pilewskie, P., Gore, W. J., Bergstrom, R. W., Román, M., Redemann, J., Russell, P. B., Liu, J., and Schaaf, C. C.: Aircraft measurements of spectral surface albedo and its consistency with ground-based and space-borne observations, J. Geophys. Res., 113, D17209, doi:10.1029/2008JD010089, 2008.

Corr, C. A., Krotkov, N., Madronich, S., Slusser, J. R., Holben, B., Gao, W., Flynn, J., Lefer, B., and Kreidenweis, S. M.: Retrieval of aerosol single scattering albedo at ultraviolet wavelengths at the T1 site during MILAGRO, Atmos. Chem. Phys., 9, 58135827, doi:10.5194/acp-9-5813-2009, 2009.

Doran, J. C., Barnard, J. C., Arnott, W. P., Cary, R., Coulter, R., Fast, J. D., Kassianov, E. I., Kleinman, L., Laulainen, N. S., Martin, T., Paredes-Miranda, G., Pekour, M. S., Shaw, W. J., Smith, D. F., Springston, S. R., and Yu, X.-Y.: The T1-T2 study: evolution of aerosol properties downwind of Mexico City, Atmos. Chem. Phys., 7, 1585-1598, doi:10.5194/acp-7-1585-2007, 2007.

Dubovik, O., Smirnov, A., Holben, B. N., King, M. D., Kaufman, Y. J., Eck, T. F., and Slutsker, I.: Accuracy assessments of aerosol optical properties retrieved from Aerosol Robotic Net- 
work (AERONET) Sun and sky radiance measurements, J. Geophys. Res., 105(D8), 9791-9806, 2000.

Hair, J. W., Hostetler, C. A., Cook, A. L., Harper, D. B., Ferrare, R. A., Mack, T. L., Welch, W., Isquierdo, L. R., and Hovis, F. E.: Airborne high spectral resolution lidar for profiling aerosol optical properties, Appl. Opt., 47, 6734-6752, 2008.

Kassianov, E. I., Flynn, C. J., Ackerman, T. P., and Barnard, J. C.: Aerosol single-scattering albedo and asymmetry parameter from MFRSR observations during the ARM Aerosol IOP 2003, Atmos. Chem. Phys., 7, 3341-3351, doi:10.5194/acp-7-3341-2007, 2007.

Kurucz, R. L.: Synthetic infrared spectra, in Infrared Solar Physics: Proceedings of the 154th Symposium of the International Astronomical Union, edited by D. M. Rabin, J. T. Jefferies, and C. Lindsey, pp. 523531, Kluwer Acad., Dordrecht, Netherlands, 1992.

Livingston, J. M., Redemann, J., Russell, P. B., Torres, O., Veihelmann, B., Veefkind, P., Braak, R., Smirnov, A., Remer, L., Bergstrom, R. W., Coddington, O., Schmidt, K. S., Pilewskie, P., Johnson, R., and Zhang, Q.: Comparison of aerosol optical depths from the Ozone Monitoring Instrument (OMI) on Aura with results from airborne sunphotometry, other space and ground measurements during MILAGRO/INTEX-B, Atmos. Chem. Phys., 9, 6743-6765, doi:10.5194/acp-9-6743-2009, 2009.

Magi, B. I., Fu, Q., Redemann, J., and Schmid, B.: Using aircraft measurements to estimate the magnitude and uncertainty of the shortwave direct radiative forcing of southern African biomass burning aerosol, J. Geophys. Res., 113, D05213, doi:10.1029/2007JD009258, 2008.

Marley, N. A., Gaffney, J. S., Castro, T., Salcido, A., and Frederick, J.: Measurements of aerosol absorption and scattering in the Mexico City Metropolitan Area during the MILAGRO field campaign: a comparison of results from the T0 and T1 sites, Atmos. Chem. Phys., 9, 189-206, doi:10.5194/acp-9-189-2009, 2009.

Mayer, B. and Kylling, A.: Technical note: The libRadtran software package for radiative transfer calculations - description and examples of use, Atmos. Chem. Phys., 5, 1855-1877, doi:10.5194/acp-5-1855-2005, 2005.

Molina, L. T., Madronich, S., Gaffney, J. S., Apel, E., de Foy, B., Fast, J., Ferrare, R., Herndon, S., Jimenez, J. L., Lamb, B., Osornio-Vargas, A. R., Russell, P., Schauer, J. J., Stevens, P. S., and Zavala, M.: An overview of the MILAGRO 2006 campaign: Mexico City emissions and their transport and transformation, Atmos. Chem. Phys. Discuss., 10, 7819-7983, doi:10.5194/acpd-10-7819-2010, 2010.

Paredes-Miranda, G., Arnott, W. P., Jimenez, J. L., Aiken, A. C., Gaffney, J. S., and Marley, N. A.: Primary and secondary contributions to aerosol light scattering and absorption in Mexico City during the MILAGRO 2006 campaign, Atmos. Chem. Phys., 9, 3721-3730, doi:10.5194/acp-9-3721-2009, 2009.
Pilewskie, P., Pommier, J., Bergstrom, R., Gore, W., Howard, S., Rabbette, M., Schmid, B., Hobbs, P. V., and Tsay, S. C.: Solar spectral radiative forcing during the Southern African Regional Science Initiative, J. Geophys. Res., 108(D13), 8486, doi:10.1029/2002JD002411, 2003.

Redemann, J., Pilewskie, P., Russell, P. B., Livingston, J. M., Howard, S., Schmid, B., Pommier, J., Gore, W., Eilers, J., and Wendisch, M.: Airborne measurements of spectral direct aerosol radiative forcing in the Intercontinental chemical Transport Experiment/Intercontinental Transport and Chemical Transformation of anthropogenic pollution, 2004, J. Geophys. Res., 111, D14210, doi:10.1029/2005JD006812, 2006.

Redemann, J., Zhang, Q., Livingston, J., Russell, P., Shinozuka, Y., Clarke, A., Johnson, R., and Levy, R.: Testing aerosol properties in MODIS Collection 4 and 5 using airborne sunphotometer observations in INTEX-B/MILAGRO, Atmos. Chem. Phys., 9, 8159-8172, doi:10.5194/acp-9-8159-2009, 2009.

Ricchiazzi, P., Yang, S. R., Gautier, C., and Sowle, D.: SBDART: A research and teaching software tool for Plane-parallell radiative transfer in the earth's atmosphere. Bulletin of the American Meteorological Society 79 (10) : 2101-2114, 1998.

Russell, P. B., Kinne, S., and Bergstrom, R.: Aerosol Climate Effects: Local Radiative Forcing and Column Closure Experiments, J. Geophys. Res., 102, 9397-9407, 1997.

Russell, P. B., Livingston, J. M., Hignett, P., Kinne, S., Wong, J., and Hobbs, P. V.: Aerosol-induced radiative flux changes off the United States Mid-Atlantic coast: Comparison of values calculated from sunphotometer and in situ data with those measured by airborne pyranometer, J. Geophys. Res., 104, 2289-2307, 1999.

Russell, P. B., J. Redemann, B. Schmid, R. W. Bergstrom, J. M. Livingston, D. M. McIntosh, S. Hartley, P. V. Hobbs, P. K. Quinn, C. M. Carrico, M. J. Rood, E. Öström, K. J. Noone, W. von Hoyningen-Huene, and L. Remer, Comparison of aerosol single scattering albedos derived by diverse techniques in two North Atlantic experiments, J. Atmos. Sci., 59, 609-619, 2002.

Wendisch, M., Müller, D., Schell, D., and Heintzenberg, J.: An airborne spectral albedometer with active horizontal stabilization, J. Atmos. Oceanic Technol., 18, 1856-1866, 2001.

Wendisch, M., Pilewskie, P., Jäkel, E., Schmidt, S., Pommier, J., Howard, S., Jonsson, H. H., Guan, H., Schröder, M., and Mayer, B.: Airborne measurements of areal spectral surface albedo over different sea and land surfaces. J. Geophys. Res., 109, D08203, doi:10.1029/2003JD004392, 2004.

Wiscombe, W. J., and Grams, G. W.: The backscattered fraction in two-stream approximations, J. Atmos. Sci., 33, 2440-2451, 1976. 